\title{
NUEVAS
}

\section{APROXIMACIONES \\ AL ESTUDIO DE LA \\ NOBLEZA Y DEL \\ COMERCIO EN LA \\ ÉPOCA COLONIAL}

Luis del Castillo Múzquiz*

RESUMEN: En las últimas décadas se han publicado trabajos relacionados con la nobleza y el comercio colonial; sin embargo, el estudio académico de ambos temas y la forma en que se relacionan es reciente. El autor explica lo anterior y hace una revisión de la historiografía, la nueva historia y la nueva nueva historia.

$$
\text { sose }
$$

ABSTRACT: In the last decades, we have seen the publication of various articles on nobility and colonial commerce however the scholarly study of these topics and their relationship is recent. The author examines the latter and summarizes its historiography, the new history, and the new new history.

PALABRAS CLAVE: nobleza colonial, comercio colonial, nueva historia, nueva nueva historia, microhistoria.

KEYWORDS: colonial nobility, colonial commerce, new history, new new history, microhistory.

RECEPCIÓN: 5 de agosto de 2008.

APROBACIÓN: $1^{\circ}$ de marzo de 2009.

* Instituto Cultural Helénico. 
CITAM Derechos Reservados.

La reproducción total o parcial de este artículo se podrá hacer si el ITAM otorga la autorización previamente por escrito. 


\section{NUEVAS}

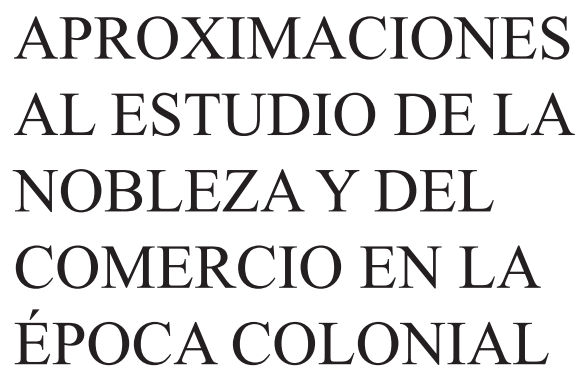

\section{La nobleza y el comercio en la Nueva España del siglo XVIII}

$\mathrm{E}_{n}$ las últimas décadas hemos sido testigos de la publicación de interesantes trabajos, relacionados con la nobleza y el comercio colonial. Sin embargo, el estudio académico de ambas cuestiones y la forma en que se relacionan es reciente. Por lo tanto, cabría proporcionar una breve explicación sobre estos temas.

Los nobles novohispanos constituyeron la élite oligárquica durante el período colonial. El hecho de poseer un título nobiliario significaba éxito económico e importancia social. Tradicionalmente, los títulos nobiliarios se otorgaban a los hombres por un útil servicio militar hecho a su rey. En el caso de la Nueva España, durante el siglo XVI y parte del siglo XVII, la Corona española fue muy cautelosa al otorgar este tipo de mercedes, por temor a que se creara una fuerte aristocracia, la cual en un momento dado pudiera amenazar el poder regio en la Colonia.

Empero, hacia el siglo XVIII, muchos hombres ajenos a las artes militares recibieron también un título nobiliario por otro tipo de servicios. En España, por ejemplo, hubo quienes fueron premiados por sus funciones administrativas en el aparato del Estado. Por otra parte, en el caso novohispano, como se verá, algunos historiadores han afirmado que la nobleza novohispana se formó con el otorgamiento de un título nobiliario a personas que habían servido al rey, mediante contribucio- 
nes económicas. Es necesario añadir aquí un matiz: si bien es cierto que en Nueva España, durante la época de la Ilustración, fueron muchos los hombres que recibieron un título como merced o gracia por el dinero prestado y/o donado a la Corona, ante ciertas necesidades de ésta, contrario a la creencia común, esto no quiere decir que los títulos se compraran a la Corona como cualquier producto en el mercado. Aunque sí llegó a haber venta de títulos por parte de la Corona, sólo ocurrió a finales del siglo XVII y principios del XVIII. Además, fueron casos excepcionales y por lo tanto no son representativos de la nobleza novohispana.

Antes de obtener el título había que cumplir con varios requisitos, tales como demostrar hidalguía (pertenecer a una familia noble); haber formado anteriormente un mayorazgo, ${ }^{1}$ el cual garantizara suficiente solvencia económica para pagar los derechos propios de los títulos nobiliarios (lanzas y media anata) y sostener un nivel de vida alto, acorde con la dignidad del título; gozar ya de cierto prestigio social, etc. Es importante subrayar el hecho de que durante el período borbónico se otorgaran títulos de Castilla tanto a funcionarios públicos (en el caso de la Península) como a comerciantes (en el caso de las colonias americanas), lo cual puede responder a una política nobiliaria ilustrada, por parte de los monarcas españoles del siglo XVIII, en especial de Carlos III, quienes estaban conscientes de que los servicios que en ese momento necesitaban más urgentemente ya no eran los militares, sino de otro tipo: en especial, los económicos, usados a su vez por el Estado para enfrentar los abundantes gastos generados por las continuas conflagraciones en las que España se vio inmersa en la época. Bien decía el doctor Bernar-

${ }^{1}$ Conjunto de bienes muebles e inmuebles entre los cuales debía figurar una vasta porción de tierra. Los mayorazgos, como su nombre lo indica, eran heredados preferentemente por los hijos mayores de cada familia y a menudo eran ampliados con los enlaces matrimoniales. Los mayorazgos solían ser indivisibles, para que no se redujera el poder del mismo. La posesión de un mayorazgo era tácitamente un requisito indispensable para obtener un título nobiliario. Para una explicación más prolija, véase Joaquín Escriche, Diccionario razonado de legislación civil, penal, comercial y forense. Con citas del derecho, notas y adiciones. Por el licenciado Juan Rodríguez de San Miguel. Edición y estudio introductorio por María del Refugio González. Reproducción en facsímil de la edición Rodríguez de San Miguel, de 1837, 1998, México, UNAM, Instituto de Investigaciones Jurídicas, Miguel Ángel Porrúa, Instituto de Estudios Parlamentarios Eduardo Neri, LV Legislatura, H. Congreso del Estado de Guerrero, pp. 422-423. 
do Contestí y Bennassar en aquella época: "la guerra se hace hoy con dineros y con navíos, y todo lo suministra el comercio".2

Lo que conocemos generalmente como nobleza novohispana es aquel grupo de oligarcas emparentados entre sí, con título nobiliario, el cual tenía el control económico y social de la colonia. Sin embargo, hablar de nobleza en el mundo hispano resulta bastante complicado, pues había varias categorías: hidalgos (nobles sin título y sin mucha riqueza), caballeros (nobles con riquezas quienes podían o no tener un hábito en alguno de las órdenes militares), títulos de Castilla (hombres que poseían título de conde o marqués) y Grandes de España (constituían la cúpula de la nobleza, eran aquellos que además de poseer título tenían una distinción, privilegios y prerrogativas mayores al resto de los nobles; cabe decir que se recibían el tratamiento de "primos del rey"). Nunca se otorgó dignidad de Grande de España a ningún residente de Nueva España, pero sí hubo, durante los tres siglos que duró la época colonial, hidalgos, caballeros y títulos de Castilla. Así entonces, el espectro de la nobleza en Nueva España resulta mucho más amplio.

Ahora bien, ese grupo de plutócratas con título de Castilla, a diferencia de la aristocracia peninsular, realizaba una serie de prácticas más relacionadas con la burguesía que con la nobleza tradicional, tales como el comercio a gran escala, préstamos de dinero a réditos, inversiones en la minería, etc. Podemos afirmar que se trataba de una aristocracia aburguesada, una alta burguesía aristocratizada o una nobleza comerciante.

Aquellos que destacaban en el comercio estaban inscritos en una de las corporaciones más poderosas de la Nueva España: el Consulado de Comercio de México. Sus miembros contaban con un gran almacén con empleados para vender sus mercancías al público. Estos encumbrados hombres recibían el apelativo de "almaceneros". Practicaban el comercio internacional y entre ellos controlaban el de la Ciudad de

${ }^{2}$ Bernardo Contestí y Bennasar, "Carta al traductor", en Gabriel François Coyer, La nobleza comerciante. Traducción del tratado que escribió en francés el abate Coyer, con un discurso preliminar y varias notas por Don Jacobo María de Spinosa y Cantabrana, del Consejo de S.M., oidor que fue de la Real Audiencia de Mallorca, y actual fiscal de la Real Audiencia de Barcelona, 1781, Madrid, Joachín Ibarra, pp. XXII-XXIII. 
México y el resto del virreinato, y además hacían funciones de banqueros cuando los particulares o la propia Corona requerían de capital líquido, casi siempre escaso durante el siglo XVIII. Sus utilidades podían llegar a los cientos de miles y en algunos casos hasta a los millones de pesos.

Por supuesto, no todos los almaceneros eran nobles, pero sí muchos de ellos. Quienes sí lo eran, pero no contaban con título, utilizaron sus pingües ganancias para elevar su posición social. Aquellos quienes ya habían nacido en la opulencia debían hacer lo posible por mantener y consolidar su condición. Aunque el dinero no bastaba para ello, era menester proyectar una imagen de súbdito leal del rey y de católico intachable. Así pues, podemos observar lo íntimamente relacionados que están ambos temas (nobleza y comercio) en la historia del siglo XVIII novohispano. Por ello los historiadores abocados al estudio de la nobleza deben tratar también el comercio y viceversa. El hecho de que la nobleza haya sido objeto de estudio por parte de connotados académicos en las últimas décadas, no significa que en el pasado nadie se haya ocupado de este grupo social; sin embargo, las menciones eran escasas, tangenciales y el tratamiento era poco serio.

\section{La nobleza novohispana en la historiografía}

Desde el siglo XIX y a lo largo de gran parte del siglo XX, el tema de la nobleza y la élite novohispana fue una veta muy poco explotada. A continuación menciono las excepciones, pero sin detenerme mucho en las obras, pues en realidad ya han sido muy superadas por trabajos monográficos que se han realizado últimamente; por lo tanto, la mayoría de las veces me limito a mencionar a los autores. De la primera mitad de la centuria ochocentista podemos citar a don Lucas Alamán y al doctor José María Luis Mora, quienes hicieron algunas menciones (más bien desdeñosas) sobre los nobles de la época colonial, en sus libros Historia de Méjico y Méjico y sus revoluciones. Hacia finales del siglo XIX, vio la luz una generación de eruditos escritores quienes comenzaron a producir obras descriptivas sobre el período virreinal, en las cuales aparecían personajes pertenecientes a la nobleza, pero sus autores no 
hacían análisis del grupo social; entre ellos encontramos a Luis González Obregón, Artemio de Valle-Arizpe, Manuel Romero de Terreros y Vinent (marqués de San Francisco). Durante el Porfiriato, época de estabilidad política y recuperación económica, Ricardo Ortega y Pérez Gallardo escribió Historia genealógica de las familias más antiguas de México, rescatando así del olvido a los antepasados de las familias más importantes del México porfirista, las cuales databan desde la época colonial. Hacia mediados del siglo XX surgió una preocupación por parte de algunos genealogistas mexicanos y extranjeros de estudiar a los nobles, entre ellos podemos mencionar a Alberto y Arturo García Carraffa, Julio Atienza, Guillermo Lohmann Villena y Leopoldo Martínez. Hacia la década de 1940 el entonces licenciado Edmundo O'Gorman publicó la transcripción de un raro, pero importante documento que trata sobre los atrasos en los pagos de lanzas y medias anatas, de los nobles en Nueva España, hacia la segunda mitad del siglo XVIII con un muy breve prólogo que precede al documento. ${ }^{3}$ Paralelamente, el historiador alemán Richard Konetzke, publicó un interesante artículo intitulado "La formación de la nobleza en Indias"; 4 sin duda se trata del primer estudio serio sobre la nobleza en Hispanoamérica. En realidad, hasta esa época la nobleza novohispana había sido tratada con prejuicios y tabúes o de forma idealizada. Algunos la creían compuesta por un grupo de hombres adinerados, pretenciosos y ridículos, quienes deseaban equipararse a los aristócratas europeos. Otros, en cambio, veían en la existencia de una nobleza en Nueva España, y en general en Hispanoamérica, la prueba de la traslación de las instituciones españolas al Nuevo Mundo y la bondad de los monarcas que gratificaban a sus súbditos aun al otro lado del Atlántico.

No sería sino hasta el último tercio del siglo XX cuando aparecieran libros que hablaran extensamente sobre la nobleza y la élite del México colonial. Los menciono a continuación, dividiéndolos en dos

${ }^{3}$ Edmundo O'Gorman, "La nobleza colonial, último tercio del siglo XVIII", Boletín del Archivo General de la Nación, enero-marzo, México, 1943, vol. XIII, núm. 4, pp. 541-589; abril-junio de 1943, vol. XIV, núm. 2, pp. 287-316; julio-septiembre de 1943, núm. 3, pp. 441-476.

${ }^{4}$ Estudios americanos. Revista de sintesis e interpretación, julio 1951, Sevilla, vol. III, núm. 10, pp. 329-357. 
bloques: los que tratan sobre la nobleza novohispana y aquellos abocados al comercio y los negocios.

En el primer bloque tenemos el de Doris Ladd, La nobleza mexicana en la época de la Independencia, $1780-1826 .{ }^{5}$ En esta obra encontramos una excelente explicación de la formación de la nobleza novohispana, así como un análisis profundo de la misma, durante las últimas décadas del Antiguo Régimen. ${ }^{6}$ Es sin duda el primer libro verdaderamente serio sobre la nobleza novohispana.

${ }^{5}$ 1984, México, FCE, tr. Marita Martínez del Río de Redo.

${ }^{6}$ Antiguo Régimen.- Los revolucionarios franceses dieron el nombre de "Antiguo Régimen" al sistema de gobierno absolutista, anterior a la Revolución. Alexis de Tocqueville publicó en 1856 su obra L'Ancien Régime et la Revolutión, consagrando así el concepto historiográficamente. Los historiadores románticos del siglo XIX marcaron la reunión de los Estados Generales, en 1789, como el comienzo de la Edad Contemporánea, pues las consecuencias generadas por el derrocamiento de la monarquía de Luis XVI alcanzarían tarde o temprano a todas las regiones del mundo occidental. Sin embargo, han existido distintos criterios y diversas opiniones para fijar el comienzo y el final del Antiguo Régimen. Algunos afirman que sus orígenes están en el Renacimiento, otros lo ubican hasta los siglos XVII y/o XVIII; pero Carlos Martínez Shaw indica que está definido por una serie de características comunes a las sociedades europeas de la Edad Moderna: "el feudalismo tardío y el capitalismo mercantil en economía, la convivencia entre los estamentos y las clases sociales, la aparición y afianzamiento de la Monarquía Absoluta como sistema político..." Por otra parte, algunos autores han aplicado el término, aludiendo a los últimos años del siglo XIX o los primeros del XX, al tratar sobre países en cuyas sociedades prevalecieron esquemas propios del Antiguo Régimen, independientemente de sus instituciones políticas. Por ejemplo, François-Xavier Guerra usa esta expresión para referirse al período anterior a la Revolución Mexicana, incluido el Porfiriato. Empero, Carlos E. Corona afirma: “el fin del Antiguo Régimen se puede datar en cada Estado por la implantación con carácter irreversible de una constitución política inspirada en la ideología revolucionaria del siglo XVIII." No obstante todo lo anterior, cuando empleo este concepto, lo hago ciñéndome a la forma en que ha sido usado por la historiografía española de las últimas décadas; es decir, como equivalente de la Edad Moderna, tomando como inicio (para el mundo hispano) el reinado de los Reyes Católicos, con la única diferencia de que si los españoles marcan su desaparición a partir de la invasión napoleónica a la Península Ibérica, considero que para el caso de México se puede establecer su final a partir de la consumación de la Independencia, en 1821. François-Xavier Guerra, México: del Antiguo Régimen a la Revolución, tr. Sergio Fernández Bravo, 2a . ed., 1991, México, FCE, vol. I, pp. 19-37. Carlos E. Corona, "Introducción al tomo séptimo", en J.O. Lindsay (Dir.), Historia del Mundo Moderno, vol. VII "El Antiguo Régimen. 1713-1763”, 1980, Barcelona, Cambridge University Press-Sopena, pp. V-XI. David Ogg, La Europa del Antiguo Régimen. 1715-1783, 1983,

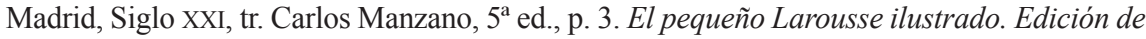
centenario, 2005, Barcelona-México-París-Buenos Aires, 11ª ed., p. 870. Manuel Abad Valera, Enrique Cantera Montenegro, Carlos Martínez Shaw e Isidro Sepúlveda Muñoz, "Glosario de tendencias historiográficas actuales (UNED)", en http://usuarios.lycos.es/tutoriasuned/glosario_de_tendencias_historiog.htm, 10/VI/2008. 
Quiero mencionar aquí una tesis inédita: La nobleza titulada en la Nueva España. Siglos XVI-XIX, presentada por Javier Eusebio Sanchiz Ruiz, para la obtención del grado de doctor en la Facultad de Filosofía y Letras de la UNAM en el año de 1996. Creo pertinente subrayar que se trata, a mi parecer, del estudio más completo sobre la nobleza novohispana titulada que hay hasta la fecha. En el texto, el doctor Sanchiz Ruiz hace un exhaustivo análisis de la nobleza novohispana en cada siglo, explicando las sutiles variaciones habidas entre cada uno de ellos; pero además relaciona acertadamente lo ocurrido en la Península Ibérica y en la Nueva España, poniendo así de manifiesto, cómo los acontecimientos de la metrópoli afectaban a la colonia, y viceversa.

Años después, Verónica Zárate Toscano publicó Los nobles ante la muerte en México. Actitudes, ceremonias y memoria (1750-1850), ${ }^{7}$ libro sumamente útil, no sólo por los datos específicos que ofrece sobre distintos personajes de la nobleza, sino por las fuentes primarias a las cuales nos remite en el Archivo General de Notarías del Distrito Federal. ${ }^{8}$ El libro gira en torno a la concepción que de la muerte tenían los nobles, lo cual nos explica una serie de importantes aspectos culturales y sociales de la época, tales como sus valores religiosos, morales, sociales, etc. Mediante su lectura se puede comprender el porqué se preocupaban tanto los nobles por pertenecer a cofradías, hacer obras pías, donaciones para educación, etc.

En el segundo bloque, relacionado con el tema del comercio y los negocios, tenemos en primer lugar el ya clásico libro de David Brading, Mineros y comerciantes en el México borbónico (1763-1810). ${ }^{9}$ En la obra, Brading nos explica el funcionamiento e importancia de las inversiones en minas y del tráfico mercantil en Nueva España, del Consulado de Comercio de la ciudad de México, así como de la red familiar constituida por la oligarquía colonial.

En segundo lugar tenemos al libro John E. Kicza, Empresarios coloniales, familias y negocios en la ciudad de México durante los Borbones. ${ }^{10}$

7 2000, México, El Colegio de México, Centro de Estudios Históricos-Instituto Mora.

${ }^{8}$ Quiero subrayar que el libro de la doctora Zárate Toscano sirve como guía en ese repositorio documental, pues a la fecha no existen guías o catálogos de los documentos del siglo XVIII que reposan ahí.

${ }^{9}$ 1975, Madrid, FCE, tr. Roberto Gómez Ciriza.

${ }^{10}$ 1986, México, FCE, tr. José Luis Luna Govea. 
Cabe decir que este libro es más un texto de historia económica que de historia social. Trata muy ampliamente todos los aspectos del comercio. Sin embargo, explica de manera muy esclarecedora el perfil que tenían los comerciantes inmigrantes peninsulares y cómo se desarrollaban una vez situados en Nueva España.

No quiero dejar de mencionar el libro de Christiana Renate Borchart de Moreno, Los mercaderes y el capitalismo en la ciudad de México: 1759-1778. ${ }^{11}$ Se trata de un complejo libro sobre la historia económica novohispana de la segunda mitad del siglo XVIII. Es muy revelador, pues explica las inversiones de la élite novohispana no sólo en el comercio, sino en otros negocios como la tierra.

Por último, creo necesario detenerme en el libro de Pedro Pérez Herrero Plata y libranzas. La articulación comercial del México borbónico, ${ }^{12}$ así como en la tesis doctoral de María Isabel Guillermina del Valle Pavón, El Consulado de comerciantes de la Ciudad de México y las finanzas novohispanas, 1592-1827.13 Ambas obras estudian meticulosamente el Consulado de Comercio de la Ciudad de México y su importancia para el gobierno virreinal y la Corona en general. El libro de Pérez Herrero destaca la importancia del crédito y el capital líquido en plata durante la segunda mitad del siglo XVIII. Por su parte, en la tesis de Del Valle

44 Pavón, podemos observar la gran utilidad que representó la Universidad de Mercaderes para el Estado, desempeñando funciones fiscales, ayudando a recaudar fondos para obras públicas, satisfaciendo las urgencias económicas de la Corona en tiempos de guerra, etc. Cabe señalar que la principal contribución de ambos autores a este trabajo es la información sobre el Tribunal mercantil; no obstante, los dos mencionan muchos datos importantes sobre sus miembros, la mayoría de los cuales, como ya se dijo, pertenecían a la nobleza.

Ahora bien, es imposible tratar el comercio y los negocios en la Nueva España borbónica sin mencionar a hombres que eran parte de la élite y de la nobleza titulada. Igualmente es imposible hacer un estudio sobre la nobleza novohispana de esa época y no adentrarse, aunque sea un

${ }^{11} 1984$, México, FCE, tr. Alejandro Zenker.

12 1988, México, El Colegio de México.

${ }^{13}$ 1997, México, tesis (doctorado en Historia), El Colegio de México. 
poco, en el comercio y otras actividades económicas como la minería, la agricultura y la ganadería.

El estudio sistemático de la élite novohispana, y en específico de la nobleza, es muy reciente. Los historiadores, tanto extranjeros como mexicanos, han tratado a este grupo de distinta manera; es decir, mientras Brading se preocupa más por asuntos económicos, Ladd se encarga de explicar a la élite como un conjunto de redes familiares que controlan lo político, lo económico y lo social. Zárate, por ejemplo, se muestra más inclinada hacia el estudio de la historia de las mentalidades. Así, en cada uno de los autores mencionados encontramos un enfoque diferente. Tal vez quien abarca más aspectos sea Sanchiz, otorgando mayor importancia a la cuestión social y al papel que tenían los nobles en ese contexto.

La consulta de estas obras, algunas de las cuales pueden ser consideradas ya como verdaderos clásicos, es insoslayable cuando se desea entender a la élite y nobleza del período colonial en su conjunto. Sin embargo, contamos también con otros textos, los cuales, si bien no estudian a la nobleza y/o élite novohispana de forma general, sí tratan sobre casos específicos, constituyéndose así en estudios microhistóricos, en los cuales, mediante el estudio meticuloso de uno o varios individuos, de una misma familia y/o una misma generación y grupo social; o de un grupo, lugar o individuo determinado, se vislumbra el contexto en que se encontraban insertos. ¿Cómo se llegó a este tipo de enfoque? La microhistoria es producto de los cambios sufridos, hacia finales de la década de 1970 y durante la de 1980, por la llamada "nueva historia".

\section{La "nueva historia" y la "nueva nueva historia"}

El término "nueva historia" es un poco ambiguo y susceptible de abuso. Se trata de una reacción surgida durante las primeras décadas del siglo XX ante el método positivista creado por Leopoldo von Ranke en la centuria anterior y fomentado por sus seguidores. Ranke había logrado sistematizar la investigación histórica mediante el uso de fuentes hasta entonces inexploradas: los documentos oficiales que reposaban en los archivos 
gubernamentales. ${ }^{14}$ Para sus contemporáneos, el célebre historiador alemán había logrado producir una historia "científica". ${ }^{15}$ No obstante, este método, utilísimo principalmente para el estudio de los temas históricos tradicionales (historia política, militar, diplomática y a veces la institucional), no resultaba el más adecuado para satisfacer los intereses de algunos científicos sociales que buscaban explicaciones sobre los procesos económicos, sociales y culturales ocurridos en el pasado. Lawrence Stone afirma que el método empleado para responder a las preguntas "qué" y "cómo" no resuelve muy bien las dudas sobre el "por qué". 16

Así, durante las primeras décadas del siglo XX surgieron científicos sociales dispuestos a desarrollar una historiografía que tomara métodos y teorías de otras disciplinas, tales como la antropología, la economía, la psicología y la sociología, la geografía, etc., las cuales llevaban ya algún tiempo desarrollándose independientemente de la historia. Aquellos vanguardistas comenzaron a ser víctimas de ataques por parte de los historiadores tradicionales y, a su vez, ellos empezaron a desdeñar a la historia tradicional, llamada por ellos "historia de los acontecimientos" ("histoire événeamentielle"). ${ }^{17}$

Realmente, la pretensión de desarrollar una nueva historiografía que rompiera con los métodos tradicionales y "obsoletos", resolviendo así una serie de obscuras incógnitas sobre el pasado, data de la Edad Antigua y continúa hasta nuestros días. En ese sentido, el método rankeano fue tan novedoso en su momento que provocó una revolución historiográfica. Durante la centuria precedente a la del célebre historiador alemán hubo algunos hombres ilustrados que propugnaban un estudio sobre el pasado, enfocado a otros aspectos, como la historia del

${ }^{14}$ Lawrence Stone, "The Revival of Narrative: Reflections on a New Old History", Past and Present, November 1979, Oxford, núm. 85, p. 5. Consultado a través de www.jstor.org, 10/01/08; Peter Burke, "Obertura: la nueva historia, su pasado y su futuro", en Peter Burke (ed.), Formas de hacer historia, 2002, Madrid, Alianza, $2^{\mathrm{a}}$ ed., tr. José Luis Gil Aristu y Francisco Martín Arribas, p. 18.

${ }^{15}$ Término igualmente ambiguo, relativo y proclive de abuso.

${ }^{16}$ Stone, op. cit., p. 5.

${ }^{17}$ Burke, op. cit., p. 21, Peter Burke, Historia y teoría social, 1992, México, Instituto Mora, tr. Stella Mastrangelo, pp. 15-25. 
derecho, del comercio, de la manera de ser y de pensar de una determinada sociedad, etc.; no obstante, para la siguiente centuria la revolución metodológica de Ranke propició un regreso rotundo a los temas tradicionales. ${ }^{18}$

Los innovadores científicos sociales de principios del siglo XX, retomando a algunos pensadores del XIX, se enfocaron en el estudio de las estructuras, en lugar de los acontecimientos, rompiendo así con la tradición. ${ }^{19}$ No obstante, hacia la década de 1970, el famoso historiador inglés Lawrence Stone notó un cambio en la "nueva historia", lo cual lo llevó a publicar en 1979 un artículo titulado "The Revival of Narrative". ${ }^{20}$ Este polémico texto es citado hasta el día de hoy por varios historiadores. En realidad es muy esclarecedor respecto al desarrollo de la "nueva historia" durante el siglo Xx y la manera como se estaba transformado hacia el momento en que fue escrito.

Lawrence Stone explica que desde 1930 hasta la década de 1970 habían florecido y predominado tres grandes escuelas de la "nueva historia": la marxista, con su conocido planteamiento sobre la lucha de clases y el control sobre los medios de producción; la de Annales, con su pretensión de lograr una "historia total", incluyendo todas las actividades humanas, mediante la interdisciplinariedad, su enfoque analítico-estructural, y su preocupación por el ambiente; y finalmente la cliometrista, ${ }^{21}$ desarrollada sobre todo en Estados Unidos. ${ }^{22}$ Sin embargo el cambio del cual Stone se percataba, era una tendencia a regresar al método narrativo. Este retorno a escribir la historia como

${ }^{18}$ Burke, “Obertura...”, pp. 21-22; Burke, Historia y teoría ..., pp. 14-18.

${ }^{19}$ Burke, "Obertura...”, p. 17, 21-22; Burke, "Historia de los acontecimientos y renacimiento de la narración", en Burke (ed.), Formas de hacer..., pp. 325-326.

${ }^{20}$ Op. cit., pp. 3-24, La traducción literal al español sería "el resurgir de la narrativa (o de la narración)".

${ }^{21}$ La cliometría es el "análisis econométrico de series largas de las cuentas nacionales, organizadas de acuerdo con modelos económicos, para dar cuenta de los procesos de crecimiento de largo plazo, de la rentabilidad social de inversiones en infraestructura o de la productividad de diversas formas de producción o de sectores específicos. [...] La cliometría consistió en la aplicación de la teoría económica y de la econometría al análisis del pasado". Salomón Kalmanovitz, "La cliometría y la historia económica institucional: reflejos latinoamericanos", Historia Crítica, enero-junio 2004, Bogotá, núm. 27. Consultada a través de http://historiacritica. uniandes.edu.co/html/27/art_kalmanovitz.htm, 19/I/2008.

${ }^{22}$ Stone, op. cit., pp. 5-7. 
narración, es decir, contando precisamente una historia, implicaba, hasta cierto punto, una vuelta a los métodos tradicionales, a la "historia de los acontecimientos".

Stone mencionaba en su artículo varios factores que influyeron en este resurgir del método narrativo para escribir la historia. Pero el más importante es el hecho de que los novedosos enfoques y metodologías empleados por aquellos historiadores hacedores de la "nueva historia" o de la "historia científica" no produjeron los resultados deseados: no fueron capaces de explicar el pasado como se esperaba. ${ }^{23}$

Esa decepción implicó una serie de nuevas preguntas sobre el pasado y, por lo tanto, nuevos enfoques y nuevas metodologías. Entre las nuevas inquietudes estaba la forma de pensar, sentir y comportarse de los individuos de antaño; es decir, lo que conocemos como "historia de las mentalidades", lo cual fue un factor determinante para la proliferación de trabajos narrativos; aunque los estudios sobre historia de las mentalidades no tengan que estar escritos, necesariamente, a manera de relato. Surgieron nuevos temas como historia de la familia, de la brujería, de la infancia, de la juventud, de la sexualidad, de las mujeres, etc. Igualmente, comenzaron a explorarse otras fuentes, antes desdeñadas, tales como documentos de procesos inquisitoriales, criminales, protocolos notariales, etc. ${ }^{24}$

Cabe aclarar que ese regreso al modelo narrativo no implicó necesariamente una vuelta a las formas tradicionales de investigar y escribir la historia, por parte de los cultivadores de la "nueva historia". Si bien, entre éstos hubo quienes empezaron a preocuparse más por individuos específicos que por la sociedad en su conjunto, se trató, más bien, del desarrollo de una nueva forma de historiografía narrativa, diferente a la tradicional en sus temas, metodología y tratamiento. Comenzó a explorarse el pasado de la gente común, no sólo el de los grandes monarcas, estadistas o militares. ${ }^{25}$

Una vez más, al conjunto de estos nuevos enfoques y métodos se le ha llamado "nueva historia". Esto último puede ser muy confuso, pues

${ }^{23}$ Ibid., pp. 8-13.

${ }^{24}$ Ibid., pp. 14-19.

${ }^{25}$ Ibid., pp. 17-24. 
la "nueva historia" de finales del siglo XX surgió como reacción a la "nueva historia" de principios y mediados de esa misma centuria, la cual pretendía ser "científica". Así pues, hay historiadores quienes llaman al cambio historiográfico de las postrimerías del siglo XX "nueva nueva historia", ${ }^{26}$ término que usaré en adelante para referirme a este cambio en la historiografía, a fin de diferenciarlo de la "nueva historia" en general.

Ahora bien, es menester precisar que la "nueva nueva historia" se ha ido practicando y desarrollando desde los últimos años de la década de 1970 hasta la fecha; además, no se limita a la historia de las mentalidades. Ahora se puede hablar de una "nueva historia política", "nueva historia militar", "nueva historia diplomática", etc., aun cuando en principio se toquen temas aparentemente tradicionales, lo novedoso puede referirse a las fuentes, la metodología de investigación y el enfoque que se dé al escribir. A la vez, perviven la historia económica, la social, la demográfica, etc. Se trata pues de una mayor apertura por parte de muchos historiadores. El famoso historiador británico Peter Burke opina respecto a la nueva historia (en general): "la nueva historia, por su parte, ha acabado interesándose por casi cualquier actividad humana [...] lo nuevo no es tanto su existencia cuanto el hecho de que quienes la practican sean ahora extremadamente numerosos y rechacen ser marginados". ${ }^{27}$ Entre las nuevas formas de hacer historia se encuentra la llamada "historia desde abajo", abocada al estudio de la gente común. ${ }^{28}$

\section{La microhistoria}

Otro de los nuevos enfoques surgidos de la "nueva nueva historia" es la microhistoria. Sus primeros cultivadores fueron Luis González y González (Pueblo en Vilo. Microhistoria de San José de Gracia), Carlo Ginzburg

${ }^{26}$ Jaume Aurell, "El nuevo medievalismo y la interpretación de los textos históricos", Hispania. Revista Española de Historia, septiembre-diciembre 2006, Madrid, vol. LXVI, núm. 224, pp. 817-818. Consultado a través de http://hispania.revistas.csic.es/, 7/XII/2007.

${ }^{27}$ Burke, “Obertura...", pp. 16 y 22.

${ }^{28}$ Ibid., pp. 17 y 24. 
(El queso y los gusanos), Emmanuel Le Roy Ladurie (Montaillou), Giovanni Levi (La herencia inmaterial), George Duby (El domingo de Bouvines), Carlo María Cipolla (Faith, Reason and the Plague in Seventeenth-Century Tuscany), Robert Darnton (The Business of Enlightenment y La gran matanza de los gatos y otros episodios de historia cultural francesa) y Natalie Davis ("Charivari, honneur et communauté à Lyon et à Genève au XVIIe siècle" y El regreso de Martin Guerre) entre otros. Los primeros estudios microhistóricos fueron publicados durante las décadas de 1970 y 1980 y abrieron la puerta para que viniesen otros más en los años subsecuentes. ${ }^{29}$

Giovanni Levi define este nuevo enfoque de la siguiente manera: "la microhistoria en cuanto práctica se basa en esencia en la reducción de la escala de observación, en un análisis microscópico y en un estudio intensivo del material documental, [...] pues los hechos mínimos y los casos individuales pueden servir para revelar fenómenos más generales. ${ }^{30}$ Los microhistoriadores comenzaron a experimentar, reduciendo la escala, a fin de que la observación microscópica les revelase factores no observados antes. Esta metodología era usada también por algunos antropólogos sociales. ${ }^{31}$

No obstante esto último, existen importantes diferencias entre la antropología interpretativa y la microhistoria. La más importante es que la microhistoria no sacrifica el conocimiento de los elementos individua-

${ }^{29}$ Luis González y González, Pueblo en Vilo. Microhistoria de San José de Gracia, 1968, México, El Colegio de México, Centro de Estudios Históricos. Cabe precisar que con esta obra y otras posteriores, Luis González fue pionero de la microhistoria y promotor de la misma en México; sin embargo, hay algunas diferencias entre las propuestas de don Luis y las de los microhistoriadores europeos y estadounidenses. Véase también Luis González y González, Invitación a la microhistoria, 1973, México, Secretaría de Educación Pública, pp. 9-28. Burke, "El debate de la microhistoria", en Burke (Ed.), Formas de hacer..., p. 141. Se trata de un apéndice informativo de pocas páginas, el cual sirve como complemento, en esta segunda edición, al artículo de Giovanni Levi "Sobre microhistoria", publicado en ambas ediciones. Burke, Historia y teoría..., pp. 52-53. Stone, op. cit., pp. 17-18. Aurell, op. cit., p. 812. Véase también la nota biográfica escrita por Arturo Acuña Borbolla, que antecede al artículo, traducido por él, de Robert Darnton, "El lector como misterio", Fractal, julio-septiembre 1996, México, Año 1, vol. 1, núm. 2, pp. 77-98. Consultado a través de http://www.fractal.com.mx/F2darn.html, 18/II/08.

${ }^{30}$ Giovanni Levi, "Sobre microhistoria", en Peter Burke (Ed.) Formas de hacer historia, 1993, Madrid, Alianza, tr. José Luis Gil Aristu, p. 122 y 140.

${ }^{31}$ Ibid., pp. 124, 126-128. Burke, Historia y teoría ..., pp. 52-54. 
les a fin de lograr una generalización amplia. Al contrario, se trata de hacer una historia de los acontecimientos de las vidas de los individuos, a fin de desvelar fenómenos generales. Es decir, sin rechazar el entorno social y su influencia, la microhistoria rescata y da importancia primordial al individuo, analizando sus actividades, comportamiento y las instituciones en que se desenvuelve. ${ }^{32}$

Peter Burke describe el nacimiento de la microhistoria de la siguiente manera:

Los historiadores sociales de las décadas de 1950 y 1960 utilizaban generalmente métodos cuantitativos, se interesaban por las vidas de millones de personas y se concentraban en el análisis de las tendencias generales, observando la vida social "desde el doceavo [sic] piso." Pero en la década de 1970, algunos de ellos dejaron el telescopio por el microscopio. ${ }^{33}$

Al comenzar el presente siglo, el mismo historiador británico dividía atinadamente los estudios microhistóricos en grupos: en primer lugar, historia sobre pueblos o aldeas; en segundo, sobre individuos particulares, y sobre familias. Ante la proliferación de este tipo de trabajos durante las postrimerías del siglo XX, Burke se preguntaba la pertinencia de seguir haciendo estudios microhistóricos, teniendo en cuenta la miríada que de ellos había. Además, señaló algunos peligros inherentes al cultivo de la microhistoria; entre ellos destacó las generalizaciones, fundadas en explicaciones reduccionistas y, por otra parte, lo anecdótico e irrelevante, convirtiendo a la microhistoria "en una especie de escapismo [...] más que en intento de explicación.” Ante esta situación, justifica la continuidad de la microhistoria siempre y cuando los distintos estudios sirvan en realidad para resolver problemas históricos. Una solución propuesta es la de vincular la microhistoria y la macrohistoria, relacionando los acontecimientos individuales con las estructuras en que tienen lugar y están insertos. ${ }^{34}$

${ }^{32}$ Levi, op. cit., pp. 132, 139-143.

${ }^{33}$ Burke, Historia y teoría..., p. 52.

${ }^{34}$ Burke, "El debate...", pp. 141-143. 
Por su parte, los españoles Anaclet Pons y Justo Serna se lanzaron en una defensa de la microhistoria; sin embargo, coincidían con Burke y con el propio Carlo Ginzburg en que no resultaba provechoso el estudio de caso per se: "la meta no debería ser sólo estudiar el caso, sino intentar analizar cómo los problemas generales que nos ocupan se dan y se viven de manera peculiar en un lugar y tiempo concretos". ${ }^{35}$ No obstante, también explican que el personaje estudiado no debe presentarse sólo como un simple ejemplo de su tiempo, como si su entorno sobrepasara completamente su voluntad individual, y como si sus acciones, logros y fracasos fueran en nada diferentes a las de sus parientes, vecinos, etc. Del mismo modo, no se le puede presentar como un ser extraño a todo lo que le rodea. ${ }^{36}$ Ahora bien, quiero concluir. Ni la microhistoria ni ninguna otra metodología histórica son panaceas y no se está exento de cometer errores.

Entre los estudios microhistóricos relacionados con la nobleza y el comercio de la época colonial, podemos mencionar el libro de María Vargas-Lobsinger, Formación y decadencia de una fortuna: los mayorazgos de San Miguel de Aguayo y de San Pedro del Álamo, 1583-1823;37 o el de Laura Pérez Rosales, Familia, poder, riqueza y subversión: los Fagoaga novohispanos, $1730-1830 .{ }^{38}$ En ambos casos, se trata de análisis de familias a lo largo de varias generaciones.

Contamos también con algunos artículos, que tratan sobre casos específicos por ejemplo: de Stanley J. Stein, "Francisco Ignacio de Yraeta y Azcárate, almacenero de la ciudad de México, 1732-1797. Un ensayo de microhistoria"; 39 de Carmen Yuste, "El conde de Tepa ante la visita de José de Gálvez"; ${ }^{40}$ y de Richmond F. Brown, "Profits, Prestige,

${ }^{35}$ Anaclet Pons y Justo Serna, "Nota sobre la microhistoria. ¿No habrá llegado el momento de parar?", Pasado y Memoria. Revista de Historia Contemporánea, 2004, Alicante. núm. 3, [edición digital del artículo], p. 23. Consultado a través de http://publicaciones.ua.es/filespubli/pdf/15793311RD39444312.pdf, 7/XII/07.

${ }^{36}$ Ibid., pp. 23-24.

${ }^{37}$ 1992, México, UNAM, Instituto de Investigaciones Históricas.

${ }^{38}$ 2003, México, Universidad Iberoamericana, Departamento de Historia-Real Sociedad Bascongada de los Amigos del País.

${ }^{39}$ Historia Mexicana, enero-marzo 2001, México, vol. L, núm. 3, pp. 459-512. Consultado a través de http://redalyc.uaemex.mx, 1/III/2007.

${ }^{40}$ Estudios de Historia Novohispana, 1991, México, vol. 11, pp. 119-134. Consultado a través de http://www.ejournal.unam.mx/historia_novo/ehn16/EHN01611.pdf, 1/III/2007. 
and Persistence: Juan Fermín de Aycinena and the Spirit of Enterprise in the Kingdom of Guatemala". ${ }^{41}$ Aunque el último estudia a un peninsular avencidado en Guatemala, puede ser muy representativo de lo que pasaba con algunos españoles que emigraban a cualquier parte de las colonias en América y varias circunstancias y la buena fortuna acababan por colocarlos en una situación privilegiada en sus nuevos lugares de residencia.

Este tipo de trabajos estudian a personajes en realidad poco conocidos. Si bien, fueron importantes y por lo tanto famosos durante su vida, su existencia no cambió el curso de la historia de un pueblo, de una nación o de una civilización y por ende han sido olvidados. Empero, a través de sus vidas podemos comprender la complejidad social y, específicamente, los pormenores de la clase o estamento a que pertenecían.

Cabe subrayar también que los estudios microhistóricos nos obligan a reflexionar sobre varios aspectos y fenómenos relacionados con los personajes tratados. Uno de ellos es el estudio de las redes sociales a las cuales pertenecían. El análisis de las mismas es otra de las nuevas aproximaciones al estudio de la nobleza, la élite y el comercio colonial.

\section{Las redes}

El estudio de redes sociales ha buscado en las últimas décadas ofrecer una nueva visión de la sociedad, en contraposición a la visión tradicional por estructuras como clases sociales, estamentos, etc. Se trata pues de ver a la sociedad como un sistema compuesto a partir de relaciones. ${ }^{42}$ Si bien, el historiador italiano Franco Ramella advierte sobre el peligro que se corre de formar un cúmulo de trabajos repetitivos que tienden a homogeneizar a los individuos, por medio de los estudios de redes, con un método y marco teórico estrictos, ${ }^{43}$ varios autores como Ramella

${ }^{41}$ The Hispanic American Historical Review, August 1995, Duke, vol. 75, núm. 3, pp. 405-440. Consultado a través de http://www.jstor.org, 17/VII/2005.

${ }^{42}$ Franco Ramella, "Por un uso fuerte del concepto de red en los estudios migratorios", en María Bjerg y Hernán Otero, Inmigración y redes sociales en la Argentina moderna, 1995, Buenos Aires, Instituto de Estudios Histórico-Sociales (IEHS)-Centro de Estudios Migratorios Latinoamericanos (CEMLA), pp. 9-14.

${ }^{43}$ Ibid., p. 12. 
y otros citados a continuación han demostrado la importancia de dichos vínculos.

Para el período colonial, podemos llamar la atención sobre algunas investigaciones de este tipo, algunas de las cuales son a la vez investigaciones microhistóricas: los artículos de Bernd Hausberger, "La conquista del empleo público en la Nueva España. El comerciante Gaditano Tomás Ruiz de Apodaca y sus amigos, siglo XVIII"; de Guillermina del Valle Pavón, "Los Excedentes del ramo Alcabalas. Habilitación de la minería y defensa del monopolio de los mercaderes de México en el siglo XVIII"; y de Antonio Ibarra, "Redes de circulación y redes de negociantes en Guadalajara colonial: mercado, élite comercial e instituciones". ${ }^{44}$ De igual manera, el libro de Paloma Fernández Pérez, El rostro familiar de la metrópoli: redes de parentesco y lazos mercantiles en Cádiz, 1700-1812, ${ }^{45}$ ofrece al lector un panorama sobre este fenómeno en el principal puerto de la España del siglo XVIII, cuyos comerciantes eran los protagonistas del comercio con las Indias occidentales. También merece la pena mencionar los trabajos de Lara Arroyo, "Redes de influencia: relaciones privilegiadas en el comercio colonial a finales del siglo XVIII: los Marticorena y su correspondencia epistolar" 46 y de Víctor Peralta Ruiz, "Camaradas políticos y paisanos. Amistad y clientelismo entre el virrey de Nueva Granada Sebastián Eslava y el marqués de la Ensenada (1741-1754)", ${ }^{47}$ los cuales explican redes de paisanaje, sociales, familiares, comerciales y políticas que van más allá del ámbito local y que se extendieron a ambos lados del océano Atlántico, entre la metrópoli y sus colonias americanas.

Creo que en los estudios de caso, los historiadores son menos susceptibles, especialmente cuando se trabaja sobre fuentes primarias, a cometer errores de precisión que los dedicados a colectividades. Además, los textos microhistóricos ayudarán a los historiadores a obtener datos más

${ }^{44}$ Todos estos artículos fueron publicados en la revista Historia Mexicana, (223), eneromarzo 2007, México, vol. LVI, núm. 3, pp. 725-778; 969-1016; y 1017-1041, respectivamente.

${ }^{45}$ 1997, Madrid, Siglo XXI.

${ }^{46}$ Nuevo Mundo Mundos Nuevos, 2007, núm. 7, versión para imprimir, 13 p., puesto en línea el 30/I/2007, http://nuevomundo.revues.org/document3213.html, 30/V/2007.

${ }^{47}$ Nuevo Mundo Mundos Nuevos, 2007, Paris, núm. 7, versión para imprimir, 12 p., puesto en línea el 9/I/2007, http://nuevomundo.revues.org/document3289.html., 30/VI/2007. 
exactos sobre los personajes tratados cuando se investigue sobre un grupo social completo o varios personajes relacionados entre sí. En resumen, considero que los estudios microhistóricos pueden ser muy útiles para la historia, ya sea social, económica, política, etc.

Aunque todos los autores citados tratan de manera diferente a la nobleza y comercio de la época virreinal, todos los estudios se complementan entre sí. Pese a que estos temas ya han sido estudiados durante algunas décadas, aún no está descubierto ni dicho todo. Entre más investigaciones haya sobre estas materias, serán menos las dudas, los prejuicios o las idealizaciones al respecto. 
CITAM Derechos Reservados.

La reproducción total o parcial de este artículo se podrá hacer si el ITAM otorga la autorización previamente por escrito. 